\title{
Long-term mechanical and shrinkage properties of cementitious grouts
}

\section{for structural repair}

\author{
Md Shamsuddoha ${ }^{{ }^{*},}$, Götz Hüsken ${ }^{a}$, Wolfram Schmidt ${ }^{a}$, Hans-Carsten Kühne ${ }^{a}$, Matthias Baeßler ${ }^{a}$ \\ a Bundesanstalt für Materialforschung und -prüfung (BAM), Unter den Eichen 87, 12205 Berlin, Germany
}

Received: 15 Fabuary 2019 / Accepted: 20 May 2019 / Published online: 24 May 2019

(C) The Author(s) 2019. This article is published with open access and licensed under a Creative Commons Attribution 4.0 International License.

\begin{abstract}
Grouts have numerous applications in construction industry such as joint sealing, structural repair, and connections in precast elements. They are particularly favoured in rehabilitation of structures due to penetrability and convenience of application. Grouts for repair applications typically require high-performance properties such as rapid strength development and superior shrinkage characteristics. Sometimes industrial by-products referred as supplementary cementitious materials (SCM) are used with neat cement due to their capabilities to provide binding properties at delayed stage. Micro silica, fly ash and metakaolin are such SCMs, those can modify and improve properties of cement products. This study aims at investigating long-term mass loss and linear shrinkage along with long-term compressive and flexural strength for grouts produced from ultrafine cement and SCMs. A series of mixtures were formulated to observe the effect of $\mathrm{SCMs}$ on these grout properties. Properties were determined after 365 days of curing at $23{ }^{\circ} \mathrm{C}$ and $55 \%$ relative humidity. The effect of SCMs on the properties are characterised by statistical models. Response surfaces were constructed to quantify these properties in relation to SCMs replacement. The results suggested that shrinkage was reduced by metakaolin, while micro silica and fly ash had positive effects on compressive and flexural strength, respectively.
\end{abstract}

Keywords: Grout; Long-term shrinkage; Micro silica; Fly ash; Metakaolin

\section{Introduction}

Although new civil constructions are being built, old structures are going through ageing process. Structural components in such structures may be cracked under service loads. Concrete or mortars are the most widely used construction materials all over the world. Unfortunately, concretes are susceptible to cracks over time due to prolonged loading. Cracks and holes in such components may threaten the safety of the whole structure. Maintenance, repair, and strengthening of structural elements then becomes a very important part of the activities of the civil industry. Sometimes it is more convenient and cheaper to repair the damaged structure than to rebuild it. Long-term properties of such grouts are crucial in relation to durability.

The grouting technique is widely used to repair civil constructions such as buildings, bridges, dams, retaining walls, and roads. In general, grouting can also be used for crack filling, compaction, fracture mitigation, reducing permeability and strengthening sub layers. Grout is injected under pressure and causes an increased strength, stiffness, and reduced permeability. Grouts can be generally divided into either a cement or chemical grout. Cement grout has two subtypes: ordinary Portland cement and ultrafine cements.
The chemical grout domain primarily includes sodium silicate, acrylic gels, epoxy and polyurethane based grouts. Cement grouting can offer an economic advantage compared to polymer grouts.

Cementitious mortar or concrete undergoes various shrinkage processes during the curing process [1]. Since grouts are placed in confined places and cracks, drying shrinkage is considered as a major concern for concrete deterioration by producing tensile stress within concrete leading to cracking. This enables harmful materials to penetrate the concrete, thereby affecting long term concrete durability. Typical in-situ curing conditions for grouts in field application usually have much lower relative humidity. It is well known that lower relative humidity results in higher shrinkage [2-4]. This may increase shrinkage cracks and mechanical properties in the long run. Hence, it is important to quantify the shrinkage especially drying shrinkage for such grouts.

Supplementary cementitious materials (SCMs) are used with ordinary Portland cement to contribute to the properties of the hardened concrete through hydraulic or pozzolanic activity or both $[5,6]$. The most commonly used SCMs are fly ash, ground granulated blast furnace slag, metakaolin and

* Corresponding author: Md Shamsuddoha, E-mail: m.shamsuddoha@unsw.edu.au 
silica fume. The incorporation of SCMs into a mortar or concrete mixture generally tends to improvement of the workability, viscosity, strength, durability, economy and reduced thermal cracking by lowering the heat of hydration. The financial advantage can further enhance when the ultrafine cement is partially replaced with supplementary cementitious materials (SCMs). Micro silica (MS), fly ash (FA), and metakaolin (MK) are commonly used pozzolanic materials [7]. However, their inclusion can affect various properties. Besides, high range water reducing admixtures are sometimes necessary to attain suitable workability properties [8]. Since three variables are involved, a parametric study is essential to carry out to attain suitable properties from an optimum range of SCMs. SCMs were also used in grouts for structural applications [9-11]. Effects of such SCMs need to be studied prior to select an optimum mix design.

This experimental study aimed at evaluating the effects of three SCMs on long-term (365-day) mechanical and linear shrinkage properties. Mix design was formulated according to Box-Behnken design approach for formulating quadratic relations. Statistic approach was used to analyse the data from the laboratory tests. Finally, effects of SCMs on the properties investigated were discussed from the plotted data.

\section{Test program}

The study was carried out in two stages. The first stage involved laboratory testing for selected mixes containing three SCMs. The later stage was statistical analysis and presentation of the responses. It is necessary to describe the approach to formulate the mix design.

\subsection{Background for statistical analysis}

Box-Behnken is one of the experimental design techniques that investigates the influence of different variables on the outcome of a controlled experiment $[12,13]$. The final aim is usually to obtain a range of input parameters for a set of outputs, which can be governed by practical applications. The optimization process involves studying the response of the statistically designed combinations, estimating the coefficients by fitting it in a mathematical model that fits best the experimental conditions, predicting the response of the fitted model and checking the adequacy of the model. This can be achieved by Response Surface Methodology (RSM), which comprises a group of statistical techniques for model building and model exploitation [14]. It allows calculations to be made of the response at intermediate levels which were not experimentally studied and shows the direction in which to move if we wish to change the input levels to decrease or increase the response.

In this study, quadratic model was used. The second-degree graduating polynomial that best represents the relation is given as Eq.(1), where $x_{i}$ refers to the input factors which influence the response, $y$. The first coefficient, $a_{x}$ represents the combination of the mean and the provision for an error adjustment. The rest of coefficients in the forms of $a_{i}$ denote individual and combined effects from three variables. Solution of these response equations was carried out using regression analysis. A graphical and statistical tool was used to create contour plots and carryout analysis of variances (ANOVA) for statistical verification.

$$
\begin{gathered}
y=a_{x}+a_{1} x_{1}+a_{2} x_{2}+a_{3} x_{3}+a_{4} x_{1}^{2}+a_{5} x_{2}^{2}+a_{6} x_{3}^{2}+ \\
a_{7} x_{1} x_{2}+a_{8} x_{1} x_{3}+a_{9} x_{2} x_{3}
\end{gathered}
$$

\subsection{Experimental design}

Total 15 test runs are required for three factors considered in this study. The contents correspond to coded values specified by Box and Behnken [12]. Table 1 shows the test matrix and ingredients. MS, $\mathrm{FA}$, and $\mathrm{MK}$ contents are kept to $(0 \%, 3 \%$, $6 \%),(0 \%, 8 \%, 16 \%)$, and $(0 \%, 8 \%, 16 \%)$, respectively. Cement was replaced with SCM contents by volume. An additional mixture (mix 16) is also shown, which represents the mixture with neat cement.

\subsection{Materials}

A micro-fine hydraulic binder was used in this study. The cement complied (except for setting time) with the requirements given by EN 197-1 for CEM I 52.5 R LA SR. Cement had $D_{95}=12 \mu \mathrm{m}$, BET specific surface $=2200 \mathrm{~m}^{2} / \mathrm{kg}$, and specific density $=3.14 \mathrm{~g} / \mathrm{cm}^{3}$. Three supplementary cementitious materials used in this study were: silica fume / micro silica (MS), Class F fly ash (FA), and metakaolin (MK), which had specific density of 2.207, 2.320, and $2.595 \mathrm{~g} / \mathrm{cm}^{3}$, respectively and $D_{95}$ was $35 \mu \mathrm{m}, 150 \mu \mathrm{m}, 20 \mu \mathrm{m}$, respectively. The chemical compositions of cement and supplementary cementitious materials are given in Table 2 .

Table 1. Mix design.

\begin{tabular}{lllllllllllllllllllll}
\hline Mix & 1 & 2 & 3 & 4 & 5 & 6 & 7 & 8 & 9 & 10 & 11 & 12 & 13 & 14 & 15 & 16 \\
\hline & Cement & 92 & 86 & 76 & 70 & 92 & 86 & 76 & 70 & 97 & 81 & 81 & 65 & 81 & 81 & 81 & 100 \\
& MS, $x_{1}$ & 0 & 6 & 0 & 6 & 0 & 6 & 0 & 6 & 3 & 3 & 3 & 3 & 3 & 3 & 3 & 0 & \\
Volume (\%) & FA, $x_{2}$ & 0 & 0 & 16 & 16 & 8 & 8 & 8 & 8 & 0 & 16 & 0 & 16 & 8 & 8 & 8 & 0 & \\
& MK, $x_{3}$ & 8 & 8 & 8 & 8 & 0 & 0 & 16 & 16 & 0 & 0 & 16 & 16 & 8 & 8 & 8 & 0 \\
\hline
\end{tabular}


Table 2. Composition of materials used.

\begin{tabular}{cllll}
\hline \multirow{2}{*}{ Chemical (\%) } & \multicolumn{3}{l}{ Materials } & \\
\cline { 2 - 5 } & Cement & $\mathrm{MS}$ & $\mathrm{FA}$ & $\mathrm{MK}$ \\
\hline $\mathrm{SiO}_{2}$ & 21.74 & 94.57 & 57.51 & 50.62 \\
$\mathrm{Al}_{2} \mathrm{O}_{3}$ & 3.79 & 0.17 & 17.02 & 42.31 \\
$\mathrm{Fe}_{2} \mathrm{O}_{3}$ & 4.08 & 0.04 & 6.99 & 1.08 \\
$\mathrm{TiO}_{2}$ & 0.18 & 0.01 & 1.32 & 0.51 \\
$\mathrm{CaO}$ & 61.47 & 1.15 & 7.81 & 0.12 \\
$\mathrm{MgO}$ & 0.95 & 0.23 & 0.64 & 0.06 \\
$\mathrm{Na} \mathrm{O}_{2} \mathrm{O}$ & 0.16 & 0.14 & 0.54 & 0.11 \\
$\mathrm{~K}_{2} \mathrm{O}$ & 0.63 & 0.71 & 1.02 & 0.88 \\
$\mathrm{Na}_{2} \mathrm{O}$ & 0.57 & - & - & - \\
(aqueous) & 0.57 & & & \\
$\mathrm{SO}_{3}$ & 2.73 & 0.21 & 0.82 & 0.15 \\
$\mathrm{P}_{2} \mathrm{O}_{5}$ & 0.10 & 0.14 & 1.09 & - \\
$\mathrm{Mn}_{2} \mathrm{O}_{3}$ & 0.18 & - & - & -- \\
$\mathrm{Cl}-$ & 0.007 & - & - & - \\
Others & 1.06 & 0.82 & 1.20 & 0.80 \\
\hline
\end{tabular}

A Polycarboxylate-ether based superplasticizer (SP) ACE 454 by BASF was used. SP was a liquid with a specific density = $1060 \mathrm{~kg} / \mathrm{m}^{3}$ and $\mathrm{pH}=6.5$. An initial test program was performed to determine the saturation point of the SP content in relation to neat cement. Flow diameter and rheological parameters showed a saturation point of $3.0 \%$ by weight of cement, below and beyond which properties showed adverse trend. Hence, a SP content of $3.0 \%$ by weight of $100 \%$ neat cement was used further in this study for all mixes. Since a finer cement was used, it was assumed that the superplasticizer had enough charges for the binders including SCMs. Based on the desire to achieve a low initial apparent viscosity value, it was decided to use this dosage by mass of dry neat cement and to apply the same dosage to all cement suspensions for reasons of uniformity and preparation simplicity, without optimizing the dosage for each specific suspension. The basis of uniform SP dosage regardless of suspension was also adopted by other researchers [15-17]. Such high SP dosage is not uncommon in literature [8], where up to $3.5 \%$ SP was used. Besides, no drastic retardation was observed in the mixtures even with the highest SCMs. During this procedure, the water content was kept low compared to typical injectable repair grout to achieve higher mechanical properties. A water-cement ratio of 0.32 (480 kg water per $\mathrm{m}^{3}$ ) was used for all mixes. Such low water content was also used by Yahia and Khayat [7].

\subsection{Test procedures}

Mixing was carried out using an intensive mortar mixer. The powders were first mixed dry for 1 minute at $400 \mathrm{rpm}$. Then, water and half of the plasticizer were added at a time and mixed for 1 minute at $400 \mathrm{rpm}$. After a resting period, second half of the plasticizer was added and mixed for another minute at the same speed. A break of 1.5 minutes in mixing was taken for scrapping the mixing container. The mix was then continued for 1 minute at $400 \mathrm{rpm}$, and finally 2 minutes at $800 \mathrm{rpm}$.

Compression and flexural tests were carried out conforming EN $196-1$ [18], where $40 \times 40 \times 160 \mathrm{~mm}$ prismatic specimens were used. Similar prismatic specimens were used to measure linear shrinkage conforming DIN EN 12617 - 4 [19].
The shrinkage was measured after initial curing of 24 hours. Same shrinkage prisms were used to determine the mass loss. Specimens for all the properties were cured in a controlled air-conditioned environment at $50 \%$ relative humidity and $23^{\circ} \mathrm{C}$ for 365 days prior to testing unlike suggested by EN 196 -1 , where submerged curing is advised. However, the prisms were cured out of the water to impose severe curing conditions, to avoid potential expansion and mass gain due to moisture absorption. Six samples were tested for each reported compressive strength and shrinkage measurement, whereas a set of three samples was tested for flexural strength. Fig.1 shows the shrinkage apparatus used for test.

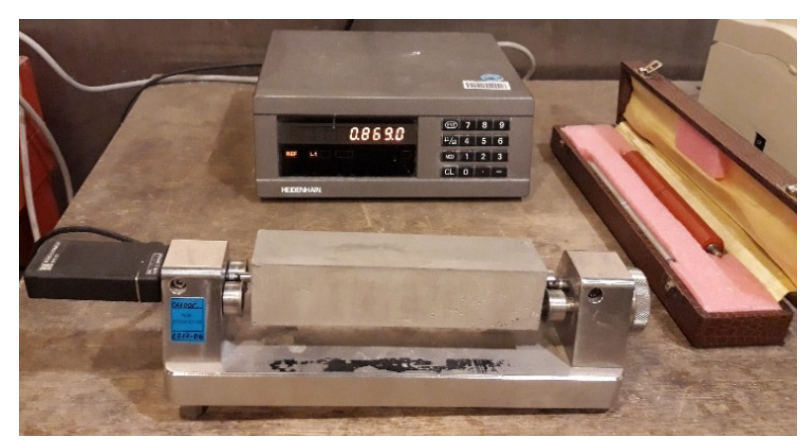

Figure 1. Shrinkage apparatus.

\section{Results and discussion}

The summary of test results obtained is given in Table 3. The results show ranges of mass loss, shrinkage, compressive strength, and flexural strength to be $5.71-8.67 \%, 0.214-$ $0.328 \%, 56.9$ - $100.5 \mathrm{MPa}$, and 2.18 to $5.81 \mathrm{MPa}$, respectively. A detailed study for such similar mixtures was already reported [20], where 28-day properties were investigated after curing at submerged condition. Compared to that study, all the mixtures have lower compressive strengths. A lower strength among the mixtures is expected since the specimens were cured at a lower relative humidity, thus creating an unfavourable hydration environment. Besides, lower strength may be also due to micro-cracking of the specimens caused by drying shrinkage gradients [21, 22].

Statistical models were developed through regression analysis. Constants mentioned in Eq.(1) were determined and outlined in Table 4. Analysis of variance (ANOVA) was also carried out considering 95\% confidence. The models show considerable accuracy with experimental results assuming a null hypothesis that the means of experimental and predicted data sets are exactly equal. Coefficient of variance, $R^{2}$ values indicates good fit of the response surfaces. This is also indicated by $P$ values, which suggest a difference is very unlikely to exist between experimental and predicted data formulated using coefficients of the table. 
Table3. Summary of 365-day test results

\begin{tabular}{|c|c|c|c|c|}
\hline Mix & Mass Loss (\%) & Linear Shrinkage (\%) & Comp. Str. (MPa) & Flex. Str. (MPa) \\
\hline 1 & $6.08 \pm 0.08$ & $0.267 \pm 0.006$ & $77.29 \pm 8.83$ & $4.64 \pm 1.55$ \\
\hline 2 & $6.09 \pm 0.04$ & $0.285 \pm 0.004$ & $73.17 \pm 5.67$ & $4.23 \pm 0.66$ \\
\hline 3 & $8.67 \pm 0.05$ & $0.324 \pm 0.004$ & $56.90 \pm 8.38$ & $4.26 \pm 1.39$ \\
\hline 4 & $7.60 \pm 0.08$ & $0.214 \pm 0.019$ & $71.28 \pm 9.09$ & $4.39 \pm 1.65$ \\
\hline 5 & $6.79 \pm 0.18$ & $0.325 \pm 0.005$ & $70.45 \pm 6.97$ & $4.08 \pm 1.07$ \\
\hline 6 & $6.84 \pm 0.08$ & $0.328 \pm 0.010$ & $72.47 \pm 5.36$ & $4.89 \pm 1.66$ \\
\hline 7 & $7.15 \pm 0.04$ & $0.278 \pm 0.007$ & $74.00 \pm 5.28$ & $3.98 \pm 1.25$ \\
\hline 8 & $7.88 \pm 0.01$ & $0.294 \pm 0.005$ & $76.81 \pm 8.77$ & $4.14 \pm 1.30$ \\
\hline 9 & $5.71 \pm 0.09$ & $0.291 \pm 0.012$ & $85.66 \pm 6.69$ & $2.18 \pm 0.27$ \\
\hline 10 & $7.24 \pm 0.14$ & $0.362 \pm 0.080$ & $65.10 \pm 6.39$ & $4.29 \pm 1.75$ \\
\hline 11 & $6.48 \pm 0.03$ & $0.277 \pm 0.010$ & $76.09 \pm 7.25$ & $4.83 \pm 1.49$ \\
\hline 12 & $8.61 \pm 0.03$ & $0.295 \pm 0.005$ & $76.81 \pm 8.72$ & $3.51 \pm 1.26$ \\
\hline 13 & $7.10 \pm 0.35$ & $0.294 \pm 0.005$ & $69.05 \pm 8.04$ & $5.27 \pm 0.56$ \\
\hline 14 & $7.11 \pm 0.05$ & $0.301 \pm 0.010$ & $79.45 \pm 8.82$ & $5.81 \pm 1.65$ \\
\hline 15 & $6.83 \pm 0.10$ & $0.282 \pm 0.002$ & $75.07 \pm 8.88$ & $5.10 \pm 1.36$ \\
\hline 16 & $6.20 \pm 0.09$ & $0.301 \pm 0.002$ & $100.50 \pm 4.93$ & $4.77 \pm 0.94$ \\
\hline
\end{tabular}

Table 4. Statistical models and analysis of variance

\begin{tabular}{|c|c|c|c|c|c|}
\hline Models & & Mass Loss & Linear Shrinkage & Comp. Str. & Flex. Str. \\
\hline \multirow{10}{*}{ Constants } & $a_{x}$ & 5.81871 & 0.28031 & 84.42629 & 2.21235 \\
\hline & $a_{1}$ & -0.06725 & 0.01174 & 1.52751 & 0.17202 \\
\hline & $a_{2}$ & 0.14239 & 0.00901 & -1.58798 & 0.30853 \\
\hline & $a_{3}$ & 0.01022 & -0.00751 & -1.16678 & 0.37693 \\
\hline & $a_{4}$ & -0.01002 & -0.00131 & 0.19515 & 0.00608 \\
\hline & $a_{5}$ & 0.00634 & 0.00018 & 0.00764 & -0.0074 \\
\hline & $a_{6}$ & 0.00218 & -0.00019 & 0.08216 & -0.01357 \\
\hline & $a_{7}$ & 0.01419 & -0.00103 & -0.41861 & -0.0224 \\
\hline & $a_{8}$ & -0.00057 & -0.00016 & -0.01965 & -0.01265 \\
\hline & $a_{9}$ & 0.00053 & 0.00038 & 0.04019 & -0.01402 \\
\hline \multirow{2}{*}{ ANOVA } & $R^{2}$ & 0.9441 & 0.8012 & 0.8963 & 0.8418 \\
\hline & $P$ & 0.9931 & 0.9746 & 0.9904 & 0.9669 \\
\hline
\end{tabular}

To portray the development of shrinkage over the 365 days period, a comparison of the grouts with median values along with neat cement grout (\#1) is shown in Fig.2. The trend suggested a sharp rise in the shrinkage up to 28 days. Then the increment slowed down for all grouts compared. The comparison also suggested that metakaolin rich system provided a lower shrinkage than that of other supplementary materials. The increment in shrinkage after 180 days are negligible and relatively stable.

The response surface produced for mass loss and shrinkage after 365 days is given in Fig.3. The results suggest that the mass loss increases with increasing fly ash and reduces with increasing micro silica. The effect of metakaolin on mass loss is negligible. Mass loss increased with increasing fly ash, whereas reduced considerably due to increment in micro silica. Linear shrinkage increases with increasing micro silica and fly ash, while reduces with increasing metakaolin. Micro silica was found to increase drying shrinkage at relative humidity less than $75 \%$ [23]. The shrinkage values seem high compared to previous studies on a range of cement pastes $[24,25]$. Several factors can contribute to this phenomenon. The reasons may be the curing at low humidity $[1,3]$. Microfine cements are known to provide higher shrinkage compared to coarser ordinary Portland cement since microfine cement hydrates much faster due to a fine pore structure, which will retain more water at a given $\mathrm{RH}$ due to osmotic suction effects [26-28]. The fact that metakaolin has positive effect on shrinkage was also reported earlier [29-31], where autogenous and long-term shrinkage were investigated. It was argued by Brooks and associates that metakaolin rich systems have lower porosity and finer pore structure, attributed to the lower amount of evaporable 
water as hydration and pozzolanic reaction used up significant amount of the free water. Up to $33 \%$ reduction in shrinkage was also reported previously for a metakaolin content of $15 \%$ [32]. However, unlike found in this study at 365 days, it was reported that higher fly ash content resulted in lower linear shrinkage at 56 days in self-compacting concrete [33].

Compressive strength increases with increasing micro silica. This trend was also reported earlier [20,34]. The response surfaces suggest that strength decreases with increasing fly ash and metakaolin in general. It is to be noted that lowest compressive strength of $56 \mathrm{MPa}$ was recorded in Table 3 when the highest fly ash (16\%) and median metakaolin (8\%) contents were added (Mixture 3). Reduction in compressive strength was also found when cement was replaced by high volume fly ash more than $30 \%$ [35]. Similar observations were also reported for cement mortars at 28 days [36]. Besides, a combination of micro silica (10\%) with fly ash resulted in higher strength in that study. The compressive strength usually increases when metakaolin content is increased, however at a lower gradient between about 80 and $70 \mathrm{MPa}$ for low MS and high FA content.
Flexural strength after 365 days was positively affected by fly ash as shown in Fig. 4(b). Micro silica content was found to have adverse effect on flexural strength. Metakaolin content had negligible effect on the strength except minor increase near $6-12 \%$ range. This trend also aligns with the previous study on mortars that bending strength reduced or remained steady when cement was replaced by metakaolin [37].

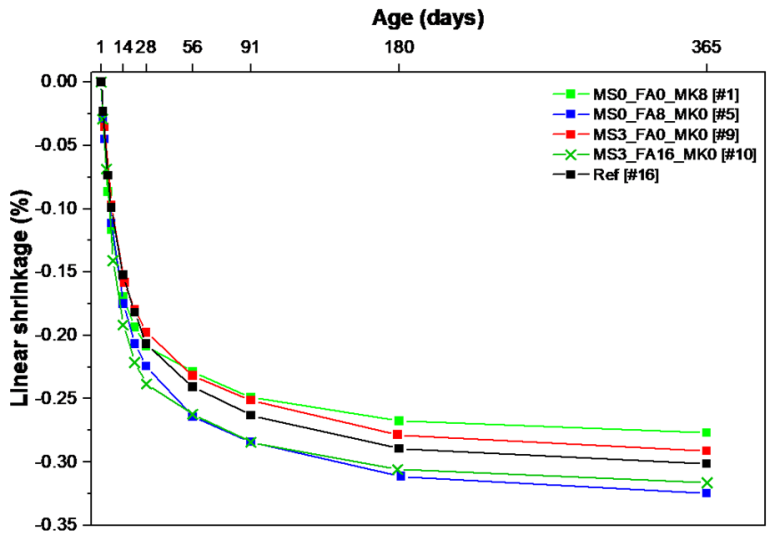

Figure 2. Typical development of linear shrinkage over time.
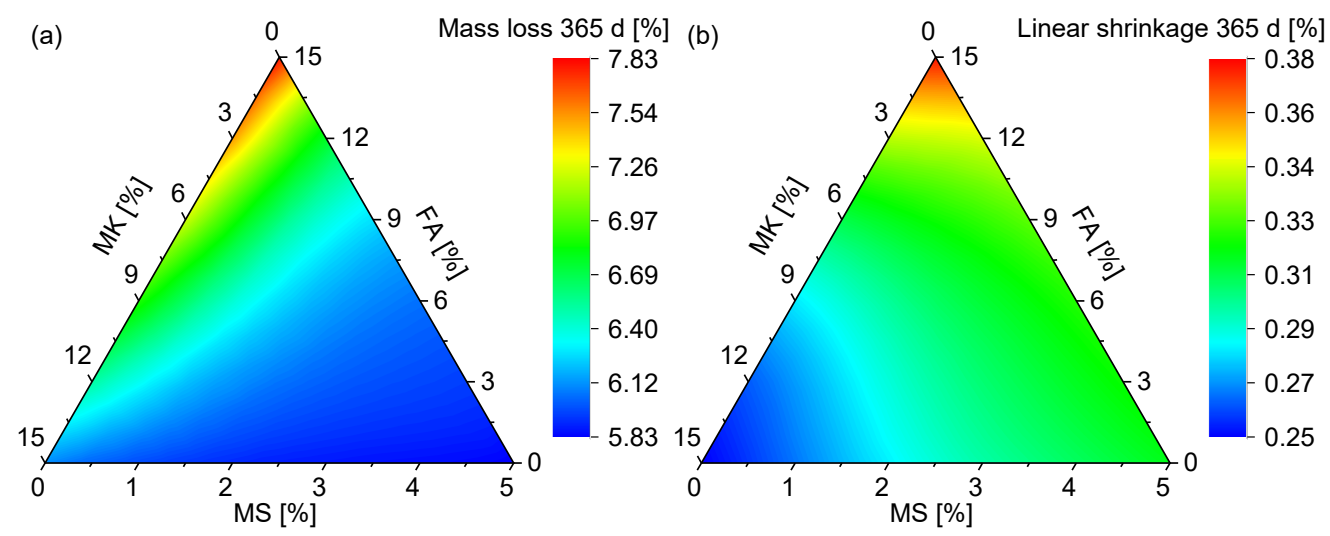

Figure 3. Effect of SCMs on long-term: (a) Mass loss, and (b) Linear shrinkage.

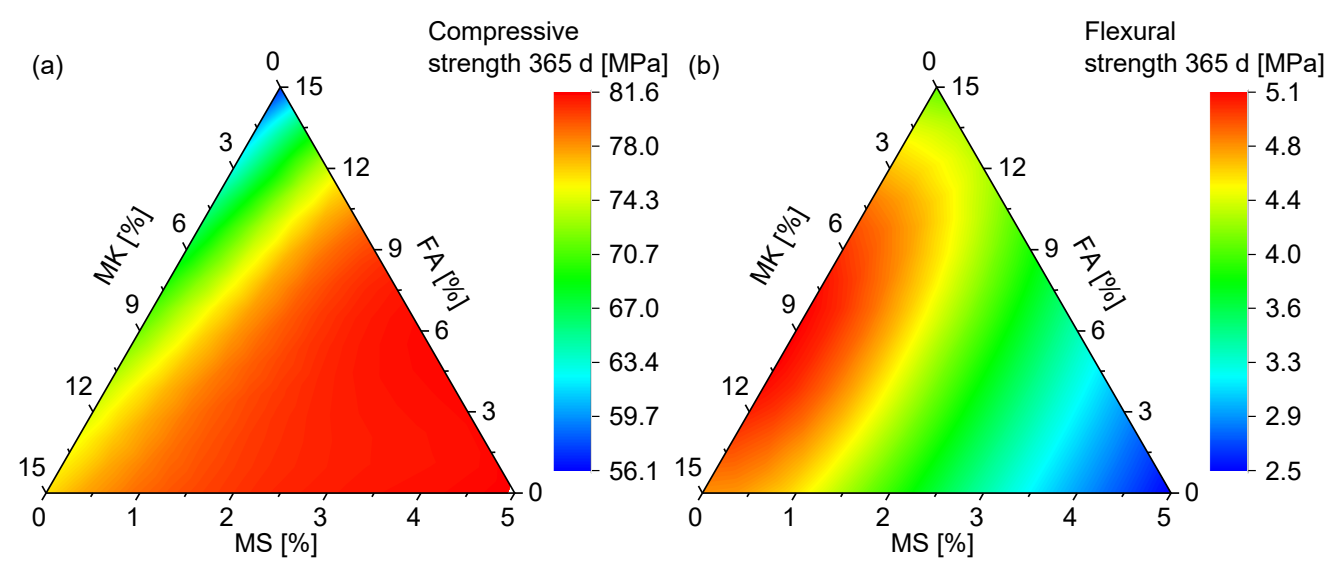

Figure 4. Effect of SCMs on long-term: (a) Compressive strength, and (b) Flexural strength. 


\section{Optimization}

A typical example of interpretation of these trends can be given in Fig. 4. An arbitrary combination of desired properties based on a set rule can be decided. In this case, it is assumed that all the desired properties will be within suitable one third of their available limits. For an example: within the total linear shrinkage range of $0.25-0.38 \%, 0.25-0.2929 \%$ provides the favourable one third of the total shrinkage range found in this study. The favourable condition for shrinkage is to keep it as low as possible. Similarly, other properties can be narrowed down to one third of their favourable ranges. The aim is to find the trend in each ingredient towards more suitable properties. Hence, an optimum zone can be obtained for a desired set of properties. The shaded area is the recommended zone for the specified set of suitable properties, which in this case is one third of each of the property ranges. From the plot, it is seen that metakaolin content higher than $7 \%$ provides a much suitable property scenario. Moreover, micro silica and fly ash contents should be lower than $1.5 \%$, and $6 \%$, respectively. Similar selection can be carried out for any other set of given properties. It should be noted that previous study of such mixtures showed that fresh properties were positively affected by fly ash and negatively affected by metakaolin, where detailed selection process of the ingredients according to their effect on fresh and 28-day hardened properties [20]. This poses a contradictory requirement for fresh and 28-day properties against long term (365-day) properties. This indicated that shrinkage should be addressed in future development of such grouts. This may be achieved by introducing shrinkage reducing admixtures in the mixture.

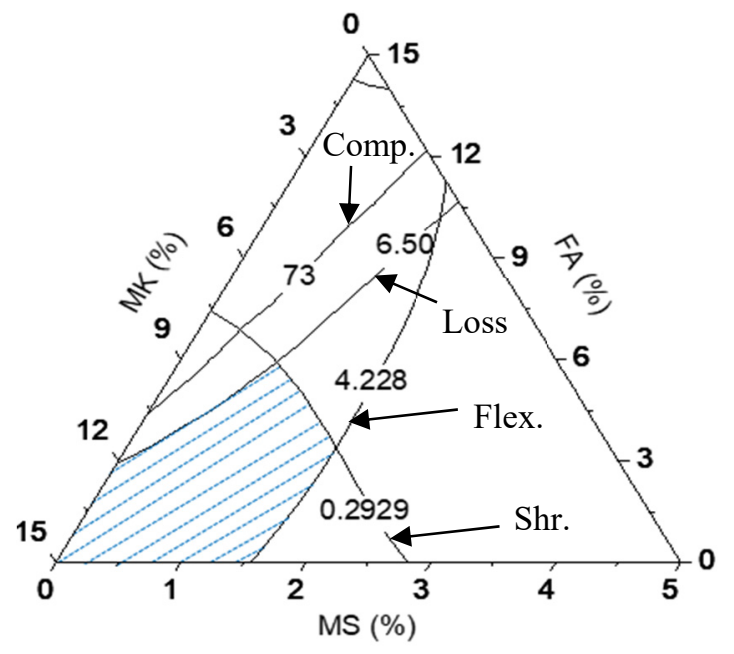

Figure 4. A typical optimization of ingredients.

\section{Conclusions}

The study was aimed to characterise the effect of replacement of ultrafine cement by three SCMs: micro silica, fly ash, and metakaolin. Sixteen grout mixtures were formulated. The samples were cured at $50 \%$ relative humidity and $23^{\circ} \mathrm{C}$ for 365 days before tested for mass loss, compressive and flexural strength. The maximum replacement by micro silica was $6 \%$, whereas a maximum of $16 \%$ was replaced by both fly ash and metakaolin. The trend in the properties were actualised using statistical models and presented through response surfaces. The results suggested that the mass loss reduced with increasing micro silica, whereas adversely affected by increasing fly ash content. Linear shrinkage reduced with increasing metakaolin, while opposite patterns were found for micro silica and fly ash. Compressive strength increased with increasing micro silica content. Whereas, fly ash had positive effect on flexural strength, which reduced for increasing micro silica content. A typical optimization technique is presented, which suggested a higher metakaolin content and lower fly ash and micro silica would provide more suitable trends of properties.

\section{References}

[1] P. Lura, O.M. Jensen, K. van Breugel, Autogenous shrinkage in highperformance cement paste: An evaluation of basic mechanisms. Cem Concr Res (2003) 33: 223-232.

https://doi.org/10.1016/S0008-8846(02)00890-6

[2] H. Samouh, E. Rozière, A. Loukili, Experimental and numerical study of the relative humidity effect on drying shrinkage and cracking of self-consolidating concrete. Cem Concr Res (2019) 115: 519-529. https://doi.org/10.1016/j.cemconres.2018.08.008

[3] J.M. Abdalhmid, A.F. Ashour, T. Sheehan, Long-term drying shrinkage of self-compacting concrete: Experimental and analytical investigations. Constr Build Mater (2019) 202: 825-837. https://doi.org/10.1016/j.conbuildmat.2018.12.152

[4] Prediction of Drying Shrinkage of Cement-Based Mortars with Poroelastic Approaches\&\#x2014;A Critical Review, in: Poromechanics VI, pp. 579-586.

[5] F. Sha, S. Li, R. Liu, Z. Li, Q. Zhang, Experimental study on performance of cement-based grouts admixed with fly ash, bentonite, superplasticizer and water glass. Constr Build Mater (2018) 161: 282-291. https://doi.org/10.1016/j.conbuildmat.2017.11.034

[6] S. Li, F. Sha, R. Liu, W. Li, Z. Li, G. Wang, Properties of Cement-Based Grouts with High Amounts of Ground Granulated Blast-Furnace Slag and Fly Ash. J Mater Civ Eng (2017) 29: 04017219. https://doi.org/10.1061/(ASCE)MT.1943-5533.0002083

[7] K.H. Obla, C.L. Lobo, H. Kim, The 2012 NRMCA Supplementary Cementitious Materials Use Survey, 2012.

[8] C.A. Anagnostopoulos, Effect of different superplasticisers on the physical and mechanical properties of cement grouts. Constr Build Mater (2014) 50: 162-168. https://doi.org/10.1016/j.conbuildmat.2013.09.050

[9] K.H. Khayat, A. Yahia, M. Sayed, Effect of Supplementary Cementitious Materials on Rheological Properties, Bleeding, and Strength of Structural Grout. ACI Mater J (2008) 105. https://doi.org/10.14359/20200

[10] C. Jolicoeur, K.H. Khayat, T. Pavate, M. Page, Evaluation of Effect of Chemical Admixture and Supplementary Cementitious Materials on Stability of Cement-Based Materials Using In-Situ Conductivity Method. ACl Sp Publ (2000) 195.

[11] A. Yahia, K.H. Khayat, Applicability of rheological models to highperformance grouts containing supplementary cementitious materials and viscosity enhancing admixture. Mater Struct (2003) 36: 402-412. https://doi.org/10.1007/BF02481066

[12] G.E.P. Box, D.W. Behnken, Some New Three Level Designs for the Study of Quantitative Variables. Technometrics (1960) 2: 455-475. https://doi.org/10.1080/00401706.1960.10489912

[13] G.E.P. Box, N.R. Draper, Empirical model-building and response surfaces, John Wiley \& Sons, New York, 1987.

[14] R.H. Myers, D.C. Montgomery, C.M. Anderson-Cook, Response surface methodology: process and product optimization using designed experiments, John Wiley \& Sons, 2016.

[15] A. Bras, R. Gião, V. Lúcio, C. Chastre, Development of an injectable grout for concrete repair and strengthening. Cem Concr Compos (2013) 37: 185-195. https://doi.org/10.1016/j.cemconcomp.2012.10.006

[16] I.A. Pantazopoulos, I.N. Markou, D.N. Christodoulou, A.I. Droudakis, D.K. Atmatzidis, S.K. Antiohos, E. Chaniotakis, Development of 
microfine cement grouts by pulverizing ordinary cements. Cem Con Comp (2012) 34: 593-603.

https://doi.org/10.1016/j.cemconcomp.2012.01.009

[17] B. Felekoğlu, Optimization of self-compacting filling grout mixtures for repair purposes. Constr Build Mater (2008) 22: 660-667. https://doi.org/10.1016/j.conbuildmat.2006.10.012

[18] European Committee for Standardization, Methods of testing cement - Part 1: Determination of strength, BS EN 196-1:2005, Brussels, 2005.

[19] Deutsches Institut für Normung e. V., Products and systems for the protection and repair of concrete structures test methods Part 4: Determination of shrinkage and expansion, DIN EN 12617-4:2002, Berlin, 2002.

[20] M. Shamsuddoha, G. Hüsken, W. Schmidt, H.-C. Kühne, M. Baeßler, Ternary mix design of grout material for structural repair using statistical tools. Constr Build Mater (2018) 189: 170-180. https://doi.org/10.1016/i.conbuildmat.2018.08.156

[21] Z.P. Bažant, M. Jirásek, Effect of Cracking and Fracture Mechanics Aspects of Creep and Shrinkage Analysis, in: Creep and Hygrothermal Effects in Concrete Structures, Springer Netherlands, Dordrecht, 2018, pp. 555-606. https://doi.org/10.1007/978-94-024-1138-6 12

[22] A.E. Idiart, C.M. López, I.J.M. Carol, Modeling of drying shrinkage of concrete specimens at the meso-level. Mater Struct (2011) 44: 415435. https://doi.org/10.1617/s11527-010-9636-2

[23] C. Di Bella, M. Wyrzykowski, P.J.M. Lura, Evaluation of the ultimate drying shrinkage of cement-based mortars with poroelastic models. Mater Struct (2016) 50: 52. https://doi.org/10.1617/s11527-016-0870-0

[24] E.-i. Tazawa, S. Miyazawa, T. Kasai, Chemical shrinkage and autogenous shrinkage of hydrating cement paste. Cem Concr Res (1995) 25: 288-292.

https://doi.org/10.1016/0008-8846(95)00011-9

[25] P. Lura, O.M. Jensen, K.v. Breugel, Autogenous deformation and RH change in Portland And blast furnace slag cement pastes, in: Secondary P. Lura, O.M. Jensen, K.v. Breugel (Eds.) Secondary Autogenous deformation and $\mathrm{RH}$ change in Portland And blast furnace slag cement pastes, Lund University, 2002, 127-137.

[26] J. Hogancamp, Z. Grasley, The use of microfine cement to enhance the efficacy of carbon nanofibers with respect to drying shrinkage crack resistance of portland cement mortars. Cem Concr Compos (2017) 83: 405-414. https://doi.org/10.1016/j.cemconcomp.2017.08.006

[27] S. Li, F. Sha, R. Liu, Q. Zhang, Z. Li, Investigation on fundamental properties of microfine cement and cement-slag grouts. Constr Build Mater (2017) 153: 965-974. https://doi.org/10.1016/j.conbuildmat.2017.05.188

[28] D.P. Bentz, E.J. Garboczi, C.J. Haecker, O.M. Jensen, Effects of cement particle size distribution on performance properties of Portland cement-based materials. Cem Concr Res (1999) 29: 16631671. https://doi.org/10.1016/S0008-8846(99)00163-5

[29] J.J. Brooks, M.A. Megat Johari, Effect of metakaolin on creep and shrinkage of concrete. Cem Concr Compos (2001) 23: 495-502. https://doi.org/10.1016/S0958-9465(00)00095-0

[30] J.J. Brooks, J.G. Cabrera, M.A. Megat Johari, Factors affecting the autogenous shrinkage of silica fume high-strength concrete, in: Secondary J.J. Brooks, J.G. Cabrera, M.A. Megat Johari (Eds.) Secondary Factors affecting the autogenous shrinkage of silica fume high-strength concrete, 1998, 185 - 192.

[31] P.J.P. Gleize, M. Cyr, G. Escadeillas, Effects of metakaolin on autogenous shrinkage of cement pastes. Cem Concr Compos (2007) 29: 80-87.

https://doi.org/10.1016/j.cemconcomp.2006.09.005

[32] J.-T. Ding, Y.-J Li, Effects of Metakaolin and Silica Fume on Properties of Concrete. ACI Mater J (2002) 99. https://doi.org/10.14359/12222

[33] J.M. Khatib, Performance of self-compacting concrete containing fly ash. Constr Build Mater (2008) 22: 1963-1971. https://doi.org/10.1016/i.conbuildmat.2007.07.011

[34] A. Allahverdi, S. Salem, Simultaneous influences of microsilica and limestone powder on properties of portland cement paste. Ceramics-Silikáty (2010) 54: 65-71.

[35] H. Yazıcı, The effect of silica fume and high-volume Class C fly ash on mechanical properties, chloride penetration and freeze-thaw resistance of self-compacting concrete. Constr Build Mater (2008) 22: 456-462.

https://doi.org/10.1016/i.conbuildmat.2007.01.002
[36] C.S. Poon, L. Lam, Y.L. Wong, A study on high strength concrete prepared with large volumes of low calcium fly ash. Cem Con Res (2000) 30: 447-455. https://doi.org/10.1016/S0008-8846(99)00271-9

[37] L. Courard, A. Darimont, M. Schouterden, F. Ferauche, X. Willem, R. Degeimbre, Durability of mortars modified with metakaolin. Cem Concr Res (2003) 33: 1473-1479.

https://doi.org/10.1016/S0008-8846(03)00090-5 